\title{
A U.R.S.S., A EDUCAÇÃO E A CULTURA: RELATOS DE VIAGEM DE INTELECTUAIS BRASILEIROS
}

\author{
Leandro Sartori Gonçalves ${ }^{1}$ \\ Carlos Alberto Barão ${ }^{2}$ \\ Gilcilene de Oliveira Damasceno Barão ${ }^{3}$
}

\section{Resumo}

O presente artigo visa analisar as produções a respeito de relatos de viagens de intelectuais comunistas - Graciliano Ramos, Jorge Amado e Pascoal Lemme - brasileiros à União das Repúblicas Socialistas Soviéticas em meados do século XX, cotejando e refletindo sobre seus significados e impactos sociais. Essa temática conta com raras produções nas áreas de história e de educação e constitui-se relevante para a história da educação sobre as experiências socialistas. O artigo inclui reflexões sobre a história da URSS; o processo de aprendizagem dos partidos comunistas; a produção ocidental a respeito dos relatos de viagem e a difamação enrustida de imparcialidade científica.

Palavras-chave: Relatos de viagem. U.R.S.S. Socialismo real. Processo de aprendizagem.

\section{THE USSR, EDUCATION AND CULTURE: TRAVEL REPORTS OF BRAZILIANS INTELECTUALS}

\begin{abstract}
This article aims to analyze the productions about travel accounts of Brazilian communist intellectuals - Graciliano Ramos, Jorge Amado and Pascoal Lemme - to the Union of Soviet Socialist Republics in the mid-twentieth century, comparing and reflecting on their meaning and social impacts. This theme has rare productions in the areas of history and education and constitutes relevant to the history of education of the socialist experiments. The article includes reflections on the history of the USSR; the learning process of the communist party; Western production about the travel accounts and closeted defamation scientific impartiality.
\end{abstract}

Keywords: Travel reports. U.S.S.R. Real socialism. Learning process.

\section{LA U.R.S.S., LA EDUCACIÓN Y LA CULTURA: RELATOS DE VIAJE DE INTELECTUALES BRASILEÑOS}

\section{Resumen}

El presente artículo busca analizar las producciones acerca de relatos de viajes de intelectuales comunistas brasileños - Graciliano Ramos, Jorge Amado y Pascoal Lemme - a 
la Unión de las Repúblicas Socialistas Soviéticas a mediados del siglo XX, cotejando y reflexionando sobre sus significados e impactos sociales. Esta temática compreende raras producciones en las áreas de historia y de educación y es relevante para la historia de la educación sobre las experiencias socialistas. El artículo incluye reflexiones sobre la historia de la URSS; el proceso de aprendizaje de los partidos comunistas; la producción occidental respecto de los relatos de viaje y la difamación desfrazada de imparcialidad científica.

Palabras clave: Relatos de viaje. U.R.S.S. Socialismo real. Proceso de aprendizaje.

\section{INTRODUÇÃO}

A Revolução ocorrida na Rússia em fins de 1917 é acontecimento histórico ímpar. A transformação engendrada com participação popular orientada pela vanguarda bolchevique destruiu o antigo regime espoliativo que existia neste país. Seus impactos se fazem sentir na conjuntura mundial durante século XX e mesmo no século XXI.

O advento do socialismo soviético estimulou o movimento comunista, as revoluções nacionais e proletárias em diversos países, ainda que atrasados economicamente. Terminada a guerra civil em 1921, a União Soviética recebe turistas desejosos de observar a construção que está em processo. Muitos visitantes relatam suas impressões pessoais e as publicam prefigurando contar o que viram e ouviram a seus conterrâneos. A educação desenvolvida no processo revolucionário torna-se um dos objetos de discussão e interesse.

No Brasil, já no início da década de 1930, são publicados alguns relatos destas viagens. Entretanto, os acontecimentos políticos e o fortalecimento do anticomunismo no país contribuíram para tergiversação sobre o tema. Após 1945, com a redemocratização no Brasil e o fim da Segunda Guerra Mundial, cresce o número de viagens e a divulgação de alguns textos sobre a educação na URSS.

Os relatos são fontes valiosas para o conhecimento de aspectos da realidade soviética relacionados às dimensões do trabalho, educação e cultura. Mesmo permeados por opções políticas de seus autores carregam elementos da história da sociedade soviética que devem ser estudados. Dessarte, trabalhar-se-á com as observações de viajantes brasileiros - os intelectuais Graciliano Ramos, Jorge Amado e Paschoal Lemme - a fim de recuperar a historicidade do padrão formativo socialista soviético. Estes autores visitaram o país socialista entre o final da década de 1940 e início da década de 1950, durante o governo de Joseph Stálin. Os relatos selecionados são: "O mundo da paz" de Jorge Amado, "Viagem" de Graciliano Ramos e “A Educação na U.R.S.S.” de Paschoal Lemme.

\section{A U.R.S.S. PERSPECTIVADA NA HISTÓRIA: UM PROCESSO DE APRENDIZAGEM}


A experiência do socialismo soviético engendrou impactos que se fizeram sentir ao longo dos séculos XX e XXI. Em especial após a segunda guerra mundial, na qual o nazismo sai derrotado pelo Exército Vermelho, o mundo capitalista teme perda de espaço político e econômico. Configura-se cisão político-ideológica, a 'guerra fria'.

Nesse contexto de guerra deve-se entender muitas produções acadêmicas e de divulgação de informações acerca dos problemas e ganhos do socialismo no Ocidente. Há que se perceber diversas são as abordagens teórico-metodológicas produzidas em análise da experiência Soviética.

Importante perceber que o entusiasmo pró-soviético do início da experiência em setores progressistas das sociedades ocidentais é, em grande medida, substituído por certa aversão à experiência socialista após a divulgação dos denominados 'crimes de Stalin'. Muitas críticas partem de um conceito abstrato de democracia ${ }^{4}$ como contraposto ao regime socialista soviético. Circunscrita ao universo burguês, a ciência política tende a essa visão abstrata, ideal e perfeita sobre a democracia. (FERNANDES, 1979, p. 9-10). As democracias populares, todavia, são dissonantes em alguns aspectos em relação a tais pressupostos. Desse modo, difunde-se entre os teóricos liberais o engabelamento que assemelha o regime soviético ao fascismo. Em geral, configura-se nesse campo teórico um 'caos terminológico': 'regime autoritário' está posto como equivalente de 'democracia forte' e o 'regime soviético' está igualado a 'totalitarismo'. (FERNANDES, 1979, p. 5-6).

Após a dissolução da URSS alguns "militantes comunistas" acabam por adquirir certa aversão ao socialismo soviético. Na maioria das vezes, tais "militantes" desprezam o real valor histórico do socialismo soviético e avaliam-no descontextualizadamente. Assim

[...] procedem não poucos comunistas: Rechaçam, indignados, a suspeita de qualquer vínculo com a história do 'socialismo real', e, reduzindo esta história a uma simples cadeia de horrores, esperam readquirir credibilidades, desta vez aos olhos da própria burguesia liberal. [...]

Aos olhos deles, o cerco imperialista ao 'socialismo real' e à revolução socialista é irrelevante [...]. (LOSURDO, 2004, p. 19).

Na visão do mesmo autor esses "comunistas" se tornam autofóbicos, aderindo a valores de opositores. É como se os comunistas tivessem tido suas consciências colonizadas pelo pensamento da ciência política burguesa, interiorizam a derrota e vociferam um "comunismo imaculado" pela "volta a Marx". Para Losurdo (2004) tem-se a adoção de uma visão religiosa dos fatos que nega o valor histórico da experiência soviética.

No sentido de negação do valor histórico da experiência indica-se duas interpretações possíveis: a primeira delas interpreta a experiência socialista sob o prisma da 'falência', indicando que a revolução fracassou. É um juízo negativo total. Por outro lado, tem-se interpretação a partir da explicação de fracasso por "traição". Presume-se, neste segundo caso, que os grandes problemas da União Soviética teriam sido causados por perfídia de 
pessoas em específico, tendendo a desconsiderar o contexto sócio-histórico. Demonizam-se certos personagens do 'socialismo real', sobretudo Stalin, e opta-se pela 'volta a Marx'.

Vejamos, em contraposição, o que Losurdo (2004, p. 45-46) nos aponta sobre a história soviética:

[...] pelo menos no que diz respeito ao período stalinista, que o horror é uma face da moeda. A outra pode ser sintetizada com algumas cifras e dados de autores insuspeitos: '[...] o quinto plano quinquenal para a educação representou um esforço organizado para combater o analfabetismo'; iniciativas posteriores no âmbito educacional desenvolveram 'toda uma geração de operários especializados e técnicos e administradores tecnicamente preparados'. Entre 1927-1928 e 19321933, o número de alunos das universidades e institutos superiores subiu de 160,000 para 470,000; o percentual dos estudantes de origem operária aumentou de um quarto para a metade. 'Novas cidades fundadas e velhas cidades reconstruídas'; o surgimento de novos gigantescos complexos industriais foi acompanhado passo a passo por uma mobilidade vertical, que mostra 'a ascensão, aos níveis superiores da escala social, de cidadãos hábeis e ambiciosos de origem operária e camponesa'. Naqueles anos, também em consequência da repressão feroz e em larga escala, 'dezenas de milhares de stakanovistas se tornam diretores de fábricas' e uma análoga, gigantesca mobilidade vertical se verificou nas forças armadas. Não se pode compreender nada do período stalinista se não se leva em conta a mescla de barbárie (um enorme gulag) e de promoção social em larga escala.

Daí a indagação: "Uma história da qual cabe apenas envergonhar-se?" (LOSURDO, 2004, p. 46). Induz-se a necessidade de esquadrinhar a experiência socialista soviética d'outra forma de maneira que se viabilize a "[...] reconquista da capacidade de pensar e agir em termos políticos." (LOSURDO, 2004, p. 24). Nesse sentido, Fernandes indica como consideração analítica importante pressuposto "[...] o partido revolucionário dos trabalhadores terá de montar várias estratégias e táticas de luta (nos planos econômico, político e ideológico), que se modificarão de uma fase para outra [...] aproveitar [o] potencial de luta revolucionária de maneira decidida e criadora." (FERNANDES, 2009, p. 47).

A reconquista da capacidade de 'pensar e agir' exige entendimento do processo contraditório e, por conseguinte, dialético do desenvolvimento real que culminou em determinadas ações do partido revolucionário. Isto está em conformidade com o pensar a história soviética como um 'processo de aprendizagem's, a partir das contradições e elementos concretos.

\section{A PRODUÇÃo OCIDENTAL A RESPEITO DOS RELATOS DE VIAGEM}

Ao considerar a experiência como processo de aprendizagem busca-se apreender o valor histórico-formativo dos relatos de viagem para aproximar-se da sociedade socialista soviética. Os relatos são aqui contrapontos as produções hegemônicas em países ocidentais a respeito das viagens à URSS. Essas produções acadêmicas prognosticam um viés analítico- 
interpretativo comum: a visão de que os viajantes estão sendo ludibriados pelos seus hospedeiros e que, por conseguinte, tendem a escrever informações inverídicas sobre a URSS.

À vista disso, muitas pessoas redigem textos que informam seus traquejos durante a visita a URSS. Kershaw estabelece, em estudos aos relatos de francesas e inglesas sobre a URSS, características gerais e comuns entre esses textos. Elas são transcritas no trecho abaixo citado:

\begin{abstract}
In works of reportage on the USSR, a first person narrator discusses the political and social changes brought about by the regime in terms of her personal experience. The texts are chronological, based on notes taken at the time, sometimes partly written during the visit or the journey home, and often amplified later by references to works of history, political analysis or to other works of reportage. They begin with an account of the journey, and mention any specific textual preparation or awareness of Russia on the part of the author. They display a determination to see if "what everyone is saying about Russia" is true, and an awareness that a great deal is indeed being said. There is some explanation of why the author chose to go, and of her political commitments, or absence thereof. They then recount the arrival, things seen and done, and people met; this is punctuated with personal reflections on "the system", which is often compared to the situation in the home country and is located in the wider context of European politics. The account of the return journey tends to be amplified by a reflection on whether or not the author is glad to leave, and there is usually a conclusion summing up the author's impressions of Russia. (KERSHAW, 2006) .
\end{abstract}

Contrariando tais estudos, aponta-se interposições com escritos de Graciliano Ramos refletindo outra tendência interpretativa. Os escritos de Graciliano Ramos, muito citado nos artigos que aqui se analisa como um dos "mais críticos" quanto a URSS, prefiguram dubiedade interpretativa. Repara-se que a leitura de trechos da obra "Viagem" isoladamente poderia prejudicar a compreensão sobre o posicionamento do autor frente a sua vivência na União Soviética. Defrontar-se-á alguns trechos deste para demonstrar nossa suposição no decorrer do texto.

Para começar, as viagens empreendidas à URSS embrenham-se não no intuito de "[...] conhecer uma civilização ou uma cultura estrangeira, e sim de descobrir e analisar um novo sistema político [...].” (MAZUY, 2002, p. 8 apud TORRES, 2012, p. 12-13). Sistema que discrepa dos padrões liberal ou monárquico, comuns até então na maior parte do globo, e por essa razão é motivo de atenção por parte de segmentos conservadores e progressistas do corpo social.

Os relatos dos viajantes costumam ser tratados como textos laudatórios a um novo sistema político e que refletem a cisão entre os "mundos irreconciliáveis"

[...] inseridos em uma luta propagandística a respeito da União Soviética e o comunismo, travada entre editoras de linha marxista, como a Pax e Calvino Filho, e editoras de literatura anticomunista, em especial a Editora Globo, de Porto Alegre, que passou a traduzir relatos contrários à URSS, em uma coleção chamada Inquéritos sobre a Rússia. (TORRES, 2012, p. 14, grifo nosso). 
Julga-se, portanto que os livros seriam tendenciosos a uma ou outra opção política, consoante a opção do escritor e visariam influir para difusão ideológica de repúdio ou solidariedade em prol da disseminação de ideias comunistas. Torres associa a ideia de que os viajantes estariam orientados por uma utopia e que escreveriam a partir de uma projeção psicológica de sua utopia - "É por isso que muitos afirmam que um relato de viagem diz muito mais sobre quem observa, do que o que é observado.” (TORRES, 2010, p. 10). Neste caso, criticando os comunistas, a autora advoga que os comunistas se contrapunham ao sistema vigente em sua própria sociedade, o capitalismo (negatividade), vislumbrando construção do socialismo como polo de positividade e progresso. Sobre isso afirma-se:

[...] a URSS em si não é ainda uma utopia na vista de seus viajantes, mas sim a confirmação da própria utopia dos criadores de tal imagem, uma vez que eles procuram passar, através de seus relatos, todos os seus valores, princípios e aspirações que creem que sejam fundamentais para a construção de uma sociedade igualitária. (TORRES, 2010, p. 9).

Ademais, deve-se acrescentar a recorrência, nas pesquisas acadêmicas que aqui tratadas, a menção às supostas 'técnicas de hospitalidade' do governo soviético. Essas técnicas serviriam na percepção dos viajantes quanto à realidade. Isto é, criar-se-ia uma atmosfera controlada na qual os viajantes veriam somente aspectos que o governo soviético consideraria oportuno serem divulgados externamente ${ }^{7}$. Dois órgãos governamentais - A Sociedade Anônima de Turismo (Intourist) e A Sociedade para as Relações Culturais da URSS com os Países Estrangeiros (Voks) - teriam por objetivo provável "[...] submeter o visitante a uma espécie de controle estatal [...]." (SOTANA, 2006, p. 146 apud FURTADO; SANTOS, 2012, p. 160).

Cabe contrapor-se a algumas destas considerações. Quanto ao fato de obter informações apenas por meio dos intérpretes pode-se verificar, em diferentes pontos do livro Viagem, que Graciliano tenta conversas diretas com moradores locais por meio de 'línguas ocidentais'. $\mathrm{O}$ autor acrescenta que às vezes ${ }^{8}$ necessitava de intérprete. Graciliano chega a mencionar que uma das primeiras perguntas feitas aos viajantes era o "[...] que desejávamos conhecer?" Aparentemente o roteiro não era tão estatelado, vejamos:

Findos os salamaleques, uma pergunta surgiu _ que desejávamos conhecer? Em seguida foi examinado o tempo necessário a isso. Duas viagens se impunham, a Leningrado e à Georgia. Em trinta dias poderíamos ir para cima, para baixo, satisfazer uma curiosidade que há longos anos crescia. Ouvindo as nossas exigências modestas, o professor expandiu-se numa alegria ruidosa: - Os senhores desejam muito pouco. Vou proceder ditatorialmente, forçando-os a visitas de que não se lembraram. (RAMOS, 2007, p. 37).

Ao ler tais fragmentos indaga-se onde estaria o 'máximo controle sobre as experiências dos viajantes'? Os passeios orientados e guiados a alguns lugares foram sim promovidos e, é bem verdade que Graciliano fica 'agradado' ao desvencilhar-se do grupo de visitantes à saída do teatro num desses passeios: 


\section{Revista HIISTEYIDIBR On-line}

Não me seria difícil orientar-me, e agradava-me ficar longe de guias e intérpretes, caminhar nas ruas só, errando, acertando, fora do carreiro de formigas, habitual desde a nossa chegada. Barbantes invisíveis nos amarravam pernas e braços, e as amabilidades excessivas começavam a pesar-me; aceitá-las parecia-me às vezes obrigação penosa. É estranho confessarmos tal coisa: não nos habituamos a gentilezas: duvidamos delas e com frequência nem as percebemos, julgamos que são endereçadas a outros indivíduos. $\mathrm{O}$ afastamento das cerimônias e cortesias surge-nos como libertação. Bons termos ensejo de quebrar a cabeça movendo-nos à toa, para cima e para baixo, procurando caminho. (RAMOS, 2007, p. 76).

Importa interrogar: o que queria ele dizer com esses tais 'barbantes invisíveis'? Frequente é a interpretação de que ele estivesse se referindo ao tal 'controle do governo'. Parece esta uma observação pessoal que se refere ao caráter cultural do país e não algo de cunho político-ditatorial. É evidente que sua referência aos 'barbantes invisíveis' está relacionada às cerimônias do país de 'hábitos diversos'. O próprio Graciliano escreve com uma pitada de acidez sobre o ditoso 'controle governamental', expondo sua indignação contra essa calúnia difundida no ocidente:

[...] A insistência dominava-me, e a repetição me deixava perplexo. Afinal não tínhamos almas. Não era bem isso: tínhamos almas diferentes das dos nossos inimigos. A revolução modificara a natureza humana. Provavelmente não se forjaram qualidades novas: desenvolveram-se as qualidades úteis, reduziram-se as nocivas. Por isso Neberidze Tamara havia escrito aquele bilhete.

Meses depois, no meu país, homens sagazes e verbosos censurar-me-iam a ignorância a respeito da União Soviética. Tinham-me os guias exibido coisas necessárias a propaganda, e eu ingênuo, acreditara nelas. Indispensável aceitar verdades ocultas muito abaixo das aparências brilhantes. E sem nunca ter ido a URSS, explicar-me-iam, generosos, horrores medonhos: trabalho forçado, enxovias horríveis, fuzilamentos diários. Seria preciso admitir que as moças do teatro Paliachvili e a menina do Instituto Marx-Engels estavam nesses lugares para enganar-me. Os transeuntes eram impostores, a serviço da polícia. As fábricas, as escolas, os palácios de pioneiros, tudo logro. Venenos do socialismo. Esforçar-se-iam por convencer-nos de que não nos movemos à vontade na terra de escravos. Atam-nos algemas invisíveis. Não as percebemos porque estamos hipnotizados, mas da América são vistas perfeitamente. Não caminhávamos livres, para cima, para baixo, à de longe, à toa. Enquanto avançávamos, Tchimakadze nos seguia de longe, dissimulando-se nas esquinas, espiando-nos. Tchimakadze era um sujeito da polícia, desse tremendo organismo onipotente e onipresente que, num mimetismo singular, fica invisível. Se encontrássemos Liúba, Assia, Keto, Nadiaja, a rapariguida do Instituto Marx-Engels, ele se aproximaria, um cigarro na mão, e me transmitiria pelo avesso as palavras delas. Nem nos deixaria gesticular, adivinharia nos rostos intuitos escondidos.

A lembrança dessa morosa estupidez, renovada com insistência lá fora, irritavame durante o passeio. (RAMOS, 2007, p. 186-188, grifo nosso).

O escritor ironiza, irritadiçamente, ao longo de seu livro a 'estupidez, renovada com insistência' pelos 'homens sagazes e verbosos' de seu país sobre a URSS. Isso pode também ser percebido já na primeira frase do livro "[...] fui a Moscou e a outros lugares medonhos situados além da cortina de ferro exposta com vigor pela civilização cristã e ocidental." (RAMOS, 2007, p. 7, grifo nosso). Pode-se entender que o tom satírico empregado no termo 
medonho deve-se ao fato de que "Circula no Ocidente uma balela cretina [...]" (RAMOS, 2007, p. 56, grifo nosso), onde era forte o anticomunismo do período que demonizava os feitos e personagens históricos soviéticos ${ }^{9}$.

No longo fragmento aqui transcrito, vê-se renovadamente elogios de Ramos à revolução, que desenvolveu qualidades humanas úteis em seus cidadãos, e, em continuidade, o deboche ao que os 'homens verbosos' do país de Graciliano, inserido na civilização cristã e ocidental, o tencionariam ver forçosamente. Os anticomunistas, 'sem nunca ter ido a URSS', seriam capazes de mencionar atrocidades cometidas no país, e afirmariam que as vivências eram como um grande teatro, uma farsa do socialismo. A realidade estaria dissimulada para enganar os visitantes 'hipnotizados', presos nas 'algemas invisíveis'. Graciliano declara-se irritado com estupidez dessas colocações.

Conclui-se que com esse trecho, Ramos parece pré-dizer, criticar e contrapor-se ao que a maioria dos pesquisadores estabeleceu como regra para analisar e definir o país socialista. Este esforço academicista é anticomunista e nega os avanços da revolução enunciados pelos relatantes visando manter o apassivamento e conformação com o status quo do corpo social burguês.

Afirma-se, pois, que Graciliano é um dos mais críticos dos viajantes em relação ao pensamento ocidental dominante, caso contrário não seria renovado em várias partes do livro seu posicionamento sarcástico em relação à visão dissimulada dos 'homens verbosos'. Encerra-se esta subseção com pelo menos duas considerações importantes sobre as conquistas da revolução e sobre a aversão do escritor pelo pensamento burguês que deturpa as conquistas revolucionárias: "Há na União Soviética uma feroz ditadura: a afirmação, no correr do tempo, entrou nos olhos e ouvidos como pregos. A ferocidade singular rouba o sono do operário dando-lhe uma educação dispendiosa em excesso." (RAMOS, 2007, p. 43). E, sobre a vida cotidiana salienta: "Ainda podemos jogar uma partida, beber uma cerveja. A ditadura horrível não nos proíbe essas necessidades cristãs.” (RAMOS, 2007, p. 100).

Alguns pesquisadores se propuseram a análise da obra "Viagem" não destacam esses elementos. De fato, preocupam-se com a frase "Pretendo ser objetivo, não derramar-me em elogios, não insinuar que, em trinta e cinco anos, a revolução de outubro haja criado um paraíso [...]" (RAMOS, 2007, p. 11) para dizer que Graciliano tinha várias críticas ao regime.

\section{“O MUNDO DA PAZ", "VIAGEM" E "A EDUCAÇÃO NA U.R.S.S.": O QUE NOS CONTAM SOBRE EDUCAÇÃO E CULTURA NA UNIÃO SOVIÉTICA?}

No livro O Mundo da Paz (1951), Jorge Amado relata suas experiências nas duas primeiras viagens empreendidas ao país socialista ${ }^{10}$. Em Viagem, Graciliano Ramos conta suas vivências durante a única viagem a URSS, em $1952^{11}$. O educador Paschoal Lemme 
escreve A Educação na U.R.S.S. (1955) após sua visita a União Soviética em 1953. Nessa obra, Paschoal concentra-se em expor como funciona a educação na URSS.

Uma ideia compartilhada pelos três autores nos relatos sobre a sociedade socialista refere-se à denominação "cortina de ferro" 12 utilizada pela imprensa para denominar a União Soviética. Jorge Amado destaca o papel da imprensa neste processo de criação de uma lenda na qual os comunistas seriam criminosos. Sucede, todavia, o contrário: "O que existe é uma cortina de dólares que uniformiza a linguagem virulenta e as notícias mentirosas sobre os países das democracias populares." (AMADO, 1951, p. 247). Em concordância, Lemme destaca o que para ele é o significado da expressão cortina de ferro: “[...] um grosseiro expediente para dificultar, até onde seja possível, que o mundo tome conhecimento de um regime que insiste em afirmar que não teme, ou melhor deseja, o confronto direto com o 'estilo de vida' de quaisquer outros." (LEMME, 1955, p. 32).

Conforme as reflexões contidas acima os acontecimentos são deturpados em favor da classe hegemônica nos países capitalistas, pois

[...] essa é a nossa liberdade de imprensa, farsa cínica com a qual enriquecem os jornais venais [...] 'liberdade de imprensa' para caluniar, injuriar e fazer pregação contra a URSS, contra os movimentos operários e democráticos [...] Sim, essa 'liberdade de imprensa' não existe na União Soviética. (AMADO, 1951, p. 219).

A imprensa soviética, ao contrário da imprensa burguesa, luta na defensa de interesses comuns: "A imprensa soviética procura armar os cidadãos para a construção da nova vida socialista, interessá-lo nela, fazer com que ele colabore ainda mais ativamente para o bem estar de todos." (AMADO, 1951, p. 221). Nela, há grande espaço reservado à fala dos próprios leitores (críticas e sugestões que abarcam aspectos da vida e do país), bem como a exposição de fatos nacionais e internacionais, nos mais variados aspectos da vida. Ela é “[...] um veículo de informação, de cultura e de educação do povo.” (LEMME, 1955, p. 252).

Tanto a imprensa quanto outros aspectos de vida cultural estão postos em patamar diverso dos países capitalistas, posto que estariam libertos

[...] das peias que a escravizavam, que a limitavam, que a tornavam propriedade de uma casta. Os trabalhadores após a revolução, encontraram em sua frente não só a possibilidade de cultivar-se, de alfabetizar-se, de educar-se, porém mais que isso, foram, por todos os meios, estimulados a fazê-lo. Elevar o nível de cultura do povo, eis uma das maiores tarefas propostas pela Revolução de Outubro ao Estado Socialista. (AMADO, 1951, p. 77).

A elevação dos níveis de cultura do povo é procedente desde tenra idade, já que as crianças passam a conhecer aspectos da vida de variados povos (apreciam poesia de Pablo Neruda, escutam histórias sobre Luiz Carlos Prestes - segundo informações de Amado). No sentido de elevação cultural Amado observa que 


\section{Revista HIIST'TEIDIBR On-line}

A criança soviética se interessa por tudo que se passa no mundo, tem horizontes muito mais amplos que os limitados, para as crianças dos países capitalistas, pelas historietas em quadrinhos, ou pelos filmes de cowboy. A literatura infantil soviética é qualquer coisa de extremamente sério qualquer coisa de extremamente magnífico. A criança soviética, educada num espírito de interesse pela vida coletiva, de solidariedade para com todos os povos, é ávida de saber o que se passam nos mais longínquos países do mundo. Fizeram-me as crianças dessa escola inumeráveis perguntas: como viviam os operários brasileiros, se existiam no Rio de Janeiro muito teatros para crianças, se os meninos brasileiros sabiam como vivem e estudam as crianças russas, se tinham palácios de pioneiros, como em Moscou. Respondi às perguntas e vi lágrimas em muitos olhos infantis. (AMADO, 1951, p. 107).

Além do conteúdo mais amplamente estudo pelos escolares soviéticos, salienta-se um clima de cordialidade e solidariedade presente no modo do novo homem relacionar-se com 'o outro', modo oriundo de uma formação humana não individualista. Ramos chega a estranhar, vejamos:

[...] fiz a mim mesmo uma pergunta. Não poderia fazer a outras pessoas: ninguém me daria resposta. Que levaria aquela gente a avizinhar-se de criaturas diversas dela em tudo? Meios diversos, hábitos diversos - divergências constrangedoras. Sociedades antagônicas. Separavam-nos distâncias imensas, externas e internas. Difícil entender-nos. E aquela gente procurava o entendimento difícil, quase impossivel $[\ldots]$

Vinham-me ao pensamento os basbaques amáveis que nos interrompiam a passagem na rua, as alunas da Escola 23, as moças do teatro Paliachvili, os camponeses do Kheivani, as professoras do sanatório, a princesa Dadiani. Por que essas manifestações, o claro intuito de invadir-nos as almas, oferecer-nos uma camaradagem possivelmente indiscreta? Encaracolados no individualismo, julgaríamos isso falta de educação: evitamos que nos mexam. E aqui vinha a dúvida. Seria essa estima, visível em toda a parte, qualidade própria da raça, de uma raça diferente da nossa, ou seria consequência de uma educação diferente da nossa? E haveria essas diferenças irredutíveis? O mais certo é terem sido criadas para enfraquecerem os homens, torná-los um rebanho de bichos inimigos uns dos outros, facilmente subjulgável. Tínhamos ali uma educação inversa à que nos davam lá fora. Devia ser isso. Em três decênios as desconfianças esmoreciam, juntavam-se as pessoas como se formassem uma grande família. (RAMOS, 2007, p. 167-168, grifo nosso).

Além da educação mais ampla e assentada em bases coletivistas, no aspecto de organização da vida muito se teria avançado quando se põe as claras as condições do trabalhador no local de trabalho: "Há na fábrica sanatório, hospital, banhos, lavandaria, estádio, casa de cultura, sala de esportes, escolas de aprendizagem, biblioteca, teatro. Numa escola normal noturna, próxima, os operários estudam sem lesar o trabalho." (RAMOS, 2007, p. 114). Estas condições leva Amado a seguinte afirmativa: "Uma multidão tranquila passa pelas ruas. Não vejo em nenhum rosto as rugas da preocupação, tão comuns em nossas cidades, onde o dinheiro dirige os destinos, não vejo a pressa nervosa dos habitantes dos centro capitalistas." (AMADO, 1951, p. 68-69).

O trabalhador soviético tem uma relação específica com a ciência e o desenvolvimento técnico, pois "[...] a ciência e a técnica eram ensinadas e aprendidas no 


\section{Revista HIISTEYIDIR On-line}

sentido de libertar o homem da opressão das formas inferiores de trabalho." (LEMME, 1955, p. 68). Para Lemme o Estado e os princípios educativos estão assentados sob outro pilar:

O fim do Estado Soviético é de fazer cada pessoa, especialmente de cada líder, um individuo social e politicamente inteligente, afim-de-que conheça os ideais e os objetivos do Estado, como também possua uma visão nítida dos seus planos, no sentido de atingir esses objetivos e tenha consciência de seu papel, como individuo nesse plano. (JONES apud LEMME, 1955, p. 244).

O desenvolvimento da consciência e do engajamento das massas passa pela educação escolarizada ou não escolar. A cultura está "[...] colocada a serviço do povo." (AMADO, 1951, p. 186). Na URSS a cultura é guia educativo da população. O intelectual e suas produções têm vinculação orgânica com o povo. As mudanças nos âmbitos das artes ou literatura se fazem sentir por meio da abordagem de temas próximos ao povo. Elas ganham significação ideológica diferenciada. De modo geral, as obras são sujeitas a apreciação pública, isto é, o povo chama o criador a discutir aspectos de suas obras, visando aprimoramento estético ou literário. O escritor está de tal maneira próximo ao trabalhador que uma operária diz alegrar-se porque pode ver "[...] que os escritores são gente de carne e osso como eu." (AMADO, 1951, p. 296).

O trabalhador comum relaciona-se com a própria escrita de modo diverso. A eles é restituído e estimulado o direito a palavra escrita. Eis o que aconteceu a um operário que escrevera sobre uma greve do antigo regime "Dessa vez, em lugar de prisões e perseguições, fui convidado a vir almoçar nesse castelo... a conhecer verdadeiros escritores... a discutir com eles... e me dizem que devo continuar a escrever, que devo procurar transformar-me num escritor profissional.” (AMADO, 1951, p. 299).

O acesso à cultura é popularizado. Os livros, a entrada a espetáculos de dança ou teatro, o ingresso para museus, etc, são vendidos por quantias módicas. Mesmo os mais simples cidadãos têm acesso. Altas tiragens de livros são produzidas e vendidas com rapidez. Há até quem se espante com a quantidade de livros nas casas dos trabalhadores. As bibliotecas são frequentemente encontradas e em geral possuem grandes quantidades de livros. A afluência ao teatro é intensa:

A arte e o luxo separavam as classes, humilharam com dureza uma delas, mas isso é história velha [...] A arte agora tem finalidade bem diferente da que lhe conferiam,

[...] A multidão invadiu a casa ilustre e aí se acha à vontade, como no trabalho ou na rua: ninguém tece lembrança de modificar um pouco a indumentária. Blusas, vestimentas pesadas, sapatões resistentes à friagem. Fardas, condecorações, as fitinhas e as medalhas vistas em toda parte, vestígios da guerra; uma pessoa arrimada à bengala, a claudicar, indica-nos estragos físicos. Mulheres gordas, vermelhas, de unhas escuras; homens rijos, ásperos, afeitos ao calor das máquinas e ao frio da cidade, a obrigação diária a exibir-se nos músculos e nos calos. Fora das luvas, as mãos apareciam grandes e nodosas. Isentas de cerimônia, essas criaturas mexiam-se, falavam alto, comiam laranjas e maçãs, jogando cascas e resíduos nos cinzeiros amarelos situados no canto da sala. num terço de século 


\section{Revista HIISTEYIDIB On-lime}

tinham-se diluído hábitos, convenções, e a rotina, a imobilidade, ali se representavam por três ou quatro figuras magras de peitos descobertos. No burburinho e no movimento, duas surpresas me chegaram: pessoas rudes, vazias na aparência, tinham recurso para ir mastigar frutos, pisar com botas grosseiras os tapetes destinados ao burguês e ao nobre; como ninguém as obrigava a passar algumas horas entregues à dança e ao canto, era necessário admitir que tinham prazer nisso. (RAMOS, 2007, p. 42-43).

Nos relatos são destacados como o teatro é aberto ao operário ajudando na sua formação, no desenvolvimento de sua sensibilidade artística. Para as crianças e jovens, é desenvolvida atividade em círculos de cultura. "Esses círculos, de filiação voluntária, reforçam o ensino comum, agrupando ao mesmo tempo, os estudantes pelas preferências que demonstram." (LEMME, 1955, p. 65).

Para além a educação extra-escolar, a educação conta com forte esfera institucional. Em se tratando da formação escolarizada, Paschoal Lemme é o autor que nos aponta os dados mais detalhados. Ele sintetiza os princípios que regem educação socialista assim:

1. A educação soviética está baseada no princípio das possibilidades iguais para todos, sem qualquer distinção de sexo, raça ou condições sociais. Condena assim, definitivamente, todas a teorias sobre a incapacidade das crianças das camadas inferiores da sociedade. Os talentos e capacidades desconhecem origens.

2.A educação soviética é integral, e consiste no desenvolvimento físico, intelectual, politécnico, moral e estético da criança e do jovem, aspectos esses intimamente relacionados entre si.

3.Na idade escolar, uma das funções principais da educação é a assimilação das bases da ciência, que reflete a realidade.

4.A ligação da teoria e da prática: todo o conhecimento resulta da experiência e tende para aplicação.

5.A educação é feita no coletivo e para o coletivo. Essa parte foi desenvolvida especialmente por Makarenko, que estabeleceu os princípios fundamentais da vida coletiva, resumidos no conceito: - A coletividade é o educador da personalidade. 6.A unidade das influencias dos professores, dos pais, da família e da escola, é outro principio básico da escola soviética.

7. O desenvolvimento da sociedade socialista é baseado no trabalho, na produção, nas exigências de uma técnica avançada. Daí, o princípio da educação politécnica, que coloca a juventude em contato direto com a produção, estabelecendo a ligação entre os princípios científicos e a técnica. (LEMME, 1955, p. 38-39).

Além disso, se tem como bases do sistema educacional os seguintes aspectos:

a - as escolas são todas mantidas pelo Estado, não havendo, como se sabe, nenhuma espécie de ensino 'particular' ou confessional. (apesar de haver ampla liberdade religiosa)

b - as escola soviéticas foram um 'sistema único, no sentido de que nelas estudam todas as crianças, sem diferença de origem social.

c - atualmente é obrigatória e gratuita a escola fundamental de sete anos. Mas, em 120 cidades, já se passou à educação obrigatória de 10 anos. No próximo quinquênio, a escola de 10 anos será obrigatória e gratuita para todos.

$\mathrm{d}$ - a escola é leiga no sentido de que não se ensina religião, não se influi de qualquer forma, sobre a consciência do aluno, e ainda mais, não se indaga quais sejam suas crenças de caráter religioso. 


\section{Revista HIIST'TEIDBR On-line}

e - a escola é perfeitamente igual para ambos os sexos. Em algumas escolas há coeducação e outra não. Somente nas grandes cidades há escolas separadas para os dois sexos (geralmente tinham caráter experimental), mas, em geral, para o país, 98\% das escolas são mistas, incluindo as rurais. Nas escolas separadas, os programas, os métodos, a quantidade de conhecimentos ministrados e os direitos conferidos pelos cursos, são absolutamente iguais para ambos os sexos. (LEMME, 1955, p. 131-132).

Segundo o mesmo autor nas escolas soviéticas haveria preocupação com preservação das línguas locais e preocupação com materiais específicos para cada região. Houve casos em que a língua local não tinha representação escrita. A despeito das críticas à uniformização dos planos de estudo, justificadas sobre prisma de defesa das regionalidades, na URSS considerar-se-ia isso um avanço, haja vista possibilidade de crianças formadas em logradouros distantes terem conhecimentos equivalentes. (LEMME, 1955).

$\mathrm{O}$ número de alunos ${ }^{13}$ seria delimitado consoante à classe: "O número máximo de alunos por classe é de 40 para $1^{\mathrm{a}}$ até a $4^{\mathrm{a}}$ séries; de 35 , da $5^{\mathrm{a}}$ à $7^{\mathrm{a}}$; e de 32 da $3^{\mathrm{a}}$ a $10^{\mathrm{a}}$ classes. Nas escolas rurais são mais abaixo ainda esses limites máximos.” (LEMME, 1955, p. 55). $\mathrm{Na}$ União Soviética, as crianças eram avaliadas por seu comportamento total. Periodicamente são aplicadas provas escritas em algumas matérias. A promoção é feita pelas médias, que variam de 0 a 5. São concedidas medalhas de ouro e pratas aos melhores alunos. (LEMME, 1955, p. 143).

Os jovens receberiam aconselhamento profissional. Ao longo de seus anos e anos de estudo, um sub-diretor pedagógico encarregar-se-ia de acompanhar o desenvolvimento intelectual e moral dos alunos. Por outro lado, um médico faz avaliações físicas e psicológicas periódicas. A vista dos dados, o aluno é aconselhado para uma ou outra profissão. Caso o aluno não tenha se identificado pode trocar de curso. (LEMME, 1955, p. 163). Após a escola de 10 anos os alunos poderiam ingressar no ensino superior. Para os alunos que finalizaram a escola de 10 anos com medalhas de ouro e prata o acesso se dá sem concurso, para os demais não.

A formação de quadros de trabalhadores técnicos estaria organizada a partir dos planos de desenvolvimento industrial. No caso, três tipos de formação eram oportunizadas:

1) As escola profissionais, encarregadas de preparar mão de obra qualificada, em tempo curto. Essas escolas dependem do Ministério das Reservas de Trabalho [...] (duração de 2 anos e não dependem de certificação anterior)

2)Os tecnicuns são estabelecimentos para formação de pessoal com nível técnico mais elevado, inclusive o que os soviéticos denominam de engenheiros práticos. Essas escolas dependiam do Ministério do Ensino Superior, atualmente incorporando a outros com a denominação de Ministério da Cultura [...] Duração de 4 anos e dependem de certificado de conclusão da escola de 7 anos)

3)Os institutos ministram técnico de nível superior [...] Os institutos formam os engenheiros e os pesquisadores. Dependem do Ministério da Cultura, para a direção pedagógica, mas os edifícios pertencem, frequentemente, aos Ministérios interessados [...] (requisito ter terminado o tecnicuns ou aescolade 10 anos). (LEMME, 1955, p. 159-162). 


\title{
Revista HIISTEYIDIR On-line
}

Ampla atenção seria dada a educação das crianças menores, como forma de garantir que as mulheres possam trabalhar. Organiza-se a educação pré-escolar consoante a regulamentação:

\begin{abstract}
Art. $1^{\circ}$ - O jardim da infância é uma instituição pública para educação de crianças de 3 à 7 anos. Tem como objetivo assegurar-lhes um desenvolvimento e uma educação completos. Ao mesmo tempo, o jardim da infância facilita a participação das mães nas tarefas da produção, na direção do Estado, na vida cultural, política e social.

Art. $2^{\circ}$ - O jardim da infância, independentemente da organização ou da instituição a que pertença, funciona de acordo com o 'Regulamento dos Jardins de Infância", com o programa e as instruções metodológicas do Ministério da Instrução Pública. Art. $3^{\circ}$ - Para cumprir os objetivos fixados no artigo primeiro do presente regulamento, os jardins de infância devem:

a - cuidar da saúde das crianças, do desenvolvimento normal e do Fortalecimento de seu organismo, promovendo de maneira exemplar a instalação e o regime da vida do jardim da infância, de acordo com os princípios higiênicos, proporcionando uma alimentação sã e completa, fazendo com que as crianças desfrutem na forma devida, de ar, água sol, regulando os jogos e exercícios físicos, e aplicando as medidas profiláticas pertinentes.

$\mathrm{b}$ - desenvolver na criança as faculdade intelectuais, a linguagem, a vontade e o caráter; educá-las artisticamente, fazendo-a compreender o mundo que a rodeia, mediante o contato direto com a natureza e o trato com as pessoas, por meio de jogos e ocupações diversas( desenho, conversação, leitura, canto, etc.), excursões e passeios.

c- habituar a crianças a valer-se de si mesma, inculcar-lhe os hábitos de higiene e de trabalho, ensinar-lhe a fazer bom uso das coisas e a ser cuidadosas.

d- habituar as crianças à ordem; educar nelas o espírito de organização; ensiná-las a comportar-se como é devido, entre as crianças e os adultos, a respeitar os mais velhos e amar seus pais. (LEMME, 1955, p. 100-101).
\end{abstract}

O professor, muito valorizado socialmente, não estaria acima das massas. Deveras, ele "[...] conquista maior estima na medida em que sua ação se funde com a dos trabalhadores, realizando um labor eminentemente social e construtivo." (LEMME, 1955, p. 257). Os professores gozariam de uma Casa do Professor, que no caso de Leningrado estivera situada num palácio. Neste local seriam promovidas diversas atividades de recreação e aperfeiçoamento para professores. Funcionaria inclusive uma faculdade para estudo do marxismo-leninismo. Quanto a questão salarial dos professores:

[...] os salários dependem do tempo de serviço e da preparação do professor. No fim de cinco anos de trabalho há um aumentos de salário correspondente a $10 \%$; no fim de 10 anos há mais um acréscimo de mais 10\%; no fim de 25 anos, mais $10 \%$ e uma pensão suplementar de 40\%. [...] O salário varia também de acordo com a região que o professor trabalha [...] O professor primário trabalha, em média, 3 a 4 horas por dia, e o secundário 3 horas. [...]

Depois de 25 anos de trabalho o professor pode jubilar-se com uma pensão correspondente a $40 \%$ do salário. Se desejar, poderá, porém, continuar trabalhando, percebendo então o salário e mais a pensão.

O limite de idade para a jubilação é de 55 anos para as mulheres e 60 anos para os homens. (LEMME, 1955, p. 54-55). 
Destaca-se que os profissionais da educação seriam majoritariamente sindicalizados, $98 \%$. Os $2 \%$ não filiados seriam iniciantes. Os sindicatos são respaldados em princípios de cooperação mútua. Eles estariam estruturados em base democrática, com eleição de representações.

Na URSS haveria preponderante interesse na formação do professorado. Assim no Ministério da Instrução Pública, seriam destacadas duas direções: “[...] a - para assuntos referentes às escolas; $\mathrm{b}$ - para as questões referentes à preparação do professor." (LEMME, 1955, p. 140).

\section{CONSIDERAÇÕES FINAIS}

A Revolução Socialista de Outubro de 1917 abriu uma nova era na história da humanidade ao provar a possibilidade real de construção do socialismo. Antes dela a mais importante experiência havia sido a Comuna de Paris, de 1871, que durou pouco mais de dois meses. Seu impacto compreende vastos territórios e populações, tendo sido muito mais amplo do que a Revolução Francesa em sua época.

A revolução Russa atraiu contra ela, desde o início, a ira das classes mais poderosas da sociedade capitalista, e o Brasil não foi uma exceção. Apenas após a II Guerra Mundial é que intelectuais da estatura de Jorge Amado, Paschoal Lemme e Graciliano Ramos puderam visitar aquele país.

As reflexões de Florestan Fernandes, sobre o falso dilema entre democracia e socialismo e as de Domenico Losurdo sobre o conceito de "aprendizagem", como fundamental para o entendimento do processo histórico soviético resultam de grande importância para o estudioso do tema. Graças a esses conceitos, e outros similares, é possível dar-se os primeiros passos para a supressão de uma concepção maniqueísta da história soviética.

O presente artigo concluiu que mesmo antes das reflexões de Florestan e Losurdo, os relatos de viagem dos três mencionados intelectuais já haviam lançado base nesse sentido. É preciso recordar que no pós guerra embora a URSS gozasse de imenso prestígio devido à vitória sobre o nazi-fascismo, já as classes dominantes no ocidente e no Brasil em particular, haviam desatado forte campanha contra ela. Lutas contra o maniqueísmo então eram, sobretudo, lutas concretamente contra conceitos como "cortina de ferro", contra o bloqueio informativo que impedia que os brasileiros tomassem contato com aquela realidade.

Jorge Amado, com sua inteligência, sensibilidade e paixão; Paschoal Lemme com a sua observação precisa e criteriosa; Graciliano Ramos, com sua dialética e sua aguda percepção dos contrates e semelhanças entre os dois países, produziram reflexões sobre os campos da educação e da cultura que hoje, mais do que nunca, deve-se resgatar, como contribuição válida para uma sociedade mais generosa em nosso país. 
As condições de vida positivas, o acesso de amplas camadas da população à educação e à cultura, a educação integral e conectada ao sistema produtivo, a educação solidaria e com forte embasamento científico e estimula a curiosidade, a preocupação constante com a coletividade e com o fortalecimento de um indivíduo culto, tais são alguns elementos fundamentais relatados pelos intelectuais mencionados ao se referirem à realidade soviética de então.

É certo também que o presente artigo representa um estímulo para o prosseguimento dos estudos sobre o tema. Em pleno século XXI a educação soviética ainda é pouco conhecida e estudada entre nós no Brasil. A continuidade desse estudo será fundamental para que deixe de ser frequente a situação tão bem relatada, com fina ironia por Graciliano em excerto aqui incluído: "Meses depois, no meu país, homens sagazes e verbosos censurar-meiam a ignorância a respeito da União Soviética [...] [Atavam-nos na viagem] Algemas invisíveis. Não os percebemos porque estamos hipnotizados, mas da América são vistos perfeitamente." (RAMOS, 2007, p. 186-188).

\section{REFERÊNCIAS}

AMADO, J. O mundo da paz. 1. ed. Rio de Janeiro: Vitória, 1951.

FERNANDES, F. Apontamentos sobre a "teoria do autoritarismo". 1. ed. São Paulo: Hucitec, 1979.

FERNANDES, F. Nós e o marxismo. 1. ed. São Paulo: Expressão Popular, 2009.

KERSHAW, A. "French and british female intellectuals and the Soviet Union. The journey to the USSR, 1929 - 1942”. 2006. Disponível em: 〈http://erea.revues.org/250>. Acesso em: 26 dez. 2014.

LEMME, P. A educação na U.R.S.S. 1. ed. Rio de Janeiro: Vitória, 1955.

LOSURDO, D. Fuga da história? A Revolução Russa e a Revolução Chinesa vistas de hoje. 1. ed. Rio de Janeiro, 2004.

MARX, K.; ENGELS, F. A ideologia alemã. Tradução de Rubens Enderle, Nelio Schneider e Luciano Cavini Martorano. 1. ed. São Paulo: Boitempo, 2007.

PRADO JÚNIOR. O mundo do socialismo. 3. ed. São Paulo: Brasiliense, 1967.

RAMOS, G. Viagem. 21. ed. Rio de Janeiro: Record, 2007.

SANTOS, A. O. A.; FURTADO, M. T. "Moscou e outros lugares medonhos": o relato de viagem de Graciliano Ramos. 2012. Disponível em: <http://revistas.fw.uri.br/index.php /revistalinguaeliteratura/article/viewFile/325/738>. Acesso em: 27 dez. 2014. 
SARTORI, L. A pedagogia da união soviética nos anos inciais da revolução socialista: primeiras aproximações. 2015. 115 f. Monografia (Graduação em Pedagogia) Universidade do Estado do Rio de Janeiro, Duque de Caxias, 2015.

TORRES, R. M. A dimensão política dos relatos de viagem no século XX: considerações a partir do estudo de relatos de viagem de brasileiros à URSS. 2012. Disponível em: <http://www.ifch.unicamp.br/ojs/index.php/rhs/article/viewFile/1215/ 847>. Acesso em: 29 dez. 2014.

TORRES, R. M. Relatos de viagem de comunistas a URSS: a confirmação de uma utopia. 2010. Disponível em: <http://www.anpuhsp.org.br/sp/downloads/CD\%20XX\%20 Encontro/PDF/Autores\%20e\%20Artigos/RaquelMundim.pdf>. Acesso em: 28 dez. 2014.

\section{Notas}

1 Possui graduação em Pedagogia pela Faculdade de Educação da Baixada Fluminense, unidade acadêmica da Universidade do Estado do Rio de Janeiro - FEBF/UERJ (2015). Foi bolsista dos projetos: de Iniciação a Docência "As contribuições de Florestan Fernandes para a Formação Docente" e do Projeto de Extensão "Educação como Política Pública: perspectiva história, embates e contradições”. É professor voluntário do Curso de Extensão "Curso de Formação de Comunidade Escolar: Literatura e Lutas na América Latina", vinculado ao Projeto de Extensão mencionado anteriormente. Atualmente cursa strictu sensu em Educação linha de pesquisa "Filosofia e História da Educação" - na Universidade Estadual de Campinas (UNICAMP). Participa como estudante no grupo HISTEDBR/Campinas e no HISTEDBRAL. Foi bolsista Capes.

2 Possui Bacharelado e Licenciatura em História Social pela Universidade Federal Fluminense (1997), mestrado em História pela Universidade Federal Fluminense (2000) e doutorado em História pela Universidade Federal Fluminense (2005). Suas principais áreas de atuação em História referem-se a História Contemporânea e História da América, com destaque para temas como Revolução Cubana, História da América Latina e História do Socialismo. Atualmente é pesquisador vinculado ao Grupo de Estudos e Pesquisas História, Sociedade e Educação no Brasil e América Latina (HISTEDBRAL).

${ }^{3}$ Possui graduação em Pedagogia pela Universidade do Estado do Rio de Janeiro (1992), especialização pela Universidade Federal Fluminense (1995), mestrado em Educação pela Universidade do Estado do Rio de Janeiro (1999) e doutorado na área de História da Educação pela Universidade Estadual de Campinas (2008). É professora adjunta da Universidade do Estado do Rio de Janeiro atuando como docente na Faculdade de Educação da Baixada Fluminense na graduação, na especialização e no programa de pós graduação em Educação, Cultura e Comunicação em periferias urbanas. Possui experiência na área de Educação, com ênfase em Política Educacional e gestão escolar. Atuando principalmente nas seguintes áreas: política educacional, história da educação, gestão democrática e escola pública. Participa como coordenadora do Projeto de Extensão "Educação, como política pública: perspectiva histórica, embates e contradições"; é pesquisadora do "Núcleo Interdisciplinar de estudo do Espaço na Baixada Fluminense"; (NIESBF) atuando na linha de pesquisa "Política Pública, Trabalho, História e Educação" (PPTHE). Coordena o curso de especialização em Gestão de processos educativos na escola. E coordena o Grupo de Estudos e Pesquisas História, Sociedade e Educação no Brasil e América Latina (HISTEDBRAL).

${ }^{4}$ Nas palavras de Florestan Fernandes(1979, p. 7) definido assim: “[...] uma democracia na qual a representação se faz tendo como base o regime eleitoral, os partidos, o parlamentarismo e o Estado constitucional. A ela é inerente forte desigualdade econômica, social e cultural com uma alta monopolização do poder pelas classes possuidoras dominantes e por suas elites. A liberdade e a igualdade são meramente formais, o que exige, $n a$ teoria e na prática, que o elemento autoritário seja intrinsecamente um componente estrutural dinâmico da preservação, do fortalecimento e da expansão do 'sistema democrático capitalista."”

5 O conceito é assim justificado por Losurdo: “[...] perder de vista o fato fundamental de que, assim como 'o desenvolvimento de um processo objetivo', também 'o desenvolvimento do conhecimento humano é pleno de 


\section{Revista HIISTESIDIB On-line}

contradições e de luta'. É esta a chave para compreender as vicissitudes que caracterizaram a história dos partidos comunistas e das sociedades que se diziam comunistas. Trata-se de enfatizar o caráter objetivamente contraditório do processo de construção da sociedade pós-capitalista e o próprio conhecimento deste processo de construção." (2004, p. 92, grifo nosso).

${ }^{6}$ Em relatos sobre a URSS, um narrador em primeira pessoa discute as mudanças políticas e sociais provocadas pelo regime a partir de sua experiência pessoal. Os textos são cronológicos, baseados nas notas escritas, ocasionalmente escritas durante a visita ou na jornada para casa, e usualmente ampliadas posteriormente por meio de referencias a trabalhos de história, análises políticas ou outros trabalhos de reportagem. Eles começam com uma descrição da jornada, e menção a alguma preparação textual específica ou conhecimento sobre a Rússia por parte do autor. Eles revelam uma determinação para verificar se 'o que todos estão dizendo sobre a Rússia' é verdade, se uma descrição fidedigna está de fato sendo feita. Há algumas explicações sobre o porquê do autor ter escolhido fazer a viajem, e seu comprometimento políticas, ou ausência dele. Eles, então, contam sobre a chegada, coisas que viram e fizeram, e pessoas que conheceram; isto é perpassado por reflexões pessoais sobre 'o sistema', as quais usualmente comparam-o a situação dos seus países de origem e sua colocação no contexto mais amplo da política europeia. A explicitação sobre o retorno tende a ser ampliada pela reflexão se o autor está ou não feliz com o que vivenciou, e há habitualmente uma conclusão sumarizando as impressões do autor sobre a Rússia. (Tradução livre dos autores).

7 “"...] estrangeiros que chegavam à URSS tinham sua permanência no país controlada pelos anfitriões, os quais se esforçavam para apresentar apenas os aspectos positivos da sociedade soviética, como também se responsabilizavam pela hospedagem e alimentação, e selecionavam quais lugares seriam visitados. Assim, os guias e intérpretes tinham um papel fundamental para que tal objetivo fosse alcançado, pois eles se empenham em fazer com que os turistas obtivessem informações dos locais que iriam frequentar apenas por meio deles." (SANTOS; FURTADO, 2012, p. 158).

8 "Em terra, a convivência obrigatória com pessoas de raças diferentes da minha, de hábitos diferentes dos meus, e a necessidade forte de entendê-las, às vezes recorrendo a três intérpretes. Na passagem de uma língua para outra, o pensamento se modifica - e era-me preciso examinar as fisionomias, buscar saber o que se encerrava em almas exóticas. A palavra não raro nos engana, e um gesto, um olhar, um sorriso, de repente nos surgiam como clarão na sombra." (RAMOS, 2007, p. 9).

9 Sobre quando Graciliano esteve próximo ao demonizado Stalin: "[...] distingui em redor vários seres que a imprensa do meu país considera monstruosos, sanguinários. Essas horríveis criaturas não me comeram." (RAMOS, 2007, p. 57).

10 O livro foi publicado no Brasil no ano de 1951 e teve cinco reedições. Ele foi traduzido para albanês, eslovaco, francês, polonês e tcheco, segundo o site da Fundação Casa de Jorge Amado. Nesse volume podemos encontrar observações das mais diversas, em elogio a URSS.

${ }^{11} \mathrm{O}$ livro publicado postumamente reúne crônicas escritas com sagacidade a partir de algumas notas pessoais tomadas ao longo da viagem. O livro tem sido considerado por pesquisadores como um dos mais críticos ao país socialista.

12 "cortina de Ferro" (em inglês "iron curtain" ): expressão criada e difundida a partir do discurso proferido por Winston Churchill na cidade de Fultan (EUA), de natureza fortemente antissoviética dando início a Guerra Fria.

13 Curiosidade interessante consta no trecho escrito por Ramos: “[...] uma ideia me veio. Em cada uma das classes que visitamos havia lugares para trinta e cinco pessoas. Trinte e seis salas. Multipliquei. (1260) A diretora nos havia falado em mil e duzentas alunas. Existia uma diferença pequena: a diretora dava-nos a lambujem de sessenta lugares. Funcionando em dois turnos, os estabelecimentos encerrariam com folga o dobro da população infantil. As garotas do primeiro ano fizeram este cálculo. E está aí por que o vírus do socialismo faz estragos medonhos nessas almas em formação. As do Brasil até agora estão imunes, livres da aritmética. (RAMOS, 2007, p. 110-111).

Submetido em: 01/05/2016

Aprovado em: 16/10/2017

Publicado em: 12/04/2018 